\title{
EXPLORANDO A GEOMETRIA DOS PISOS E DOS FRISOS POR MEIO DO SOFTWARE GEOGEBRA ${ }^{1}$
}

\author{
Gicele da Rocha Rossi - UNIFRA, Santa Maria - RS \\ (gicelerossi@yahoo.com.br) \\ Eleni Bisognin - UNIFRA, Santa Maria - RS- (eleni@unifra.br)
}

\begin{abstract}
Resumo
O propósito desse trabalho é apresentar alguns resultados parciais de uma pesquisa do tipo qualitativa realizada com alunos da sexta série do Ensino Fundamental, utilizando-se a Engenharia Didática. Foram abordadas as transformações geométricas no plano tais como, reflexões, translações e rotações com o objetivo de analisar as contribuições da utilização de um programa computacional, como o GeoGebra, para o ensino de Matemática. Com esse propósito, foi elaborada uma página html contendo atividades referentes a esses tópicos. Pôde-se inferir, da análise dos resultados, que a utilização desses recursos computacionais propiciou a criação de um ambiente interativo em sala de aula, facilitando uma abordagem intuitiva e de experimentação da Geometria, que despertou o espírito investigativo do aluno e o tornou um participante ativo no processo de aprendizagem.
\end{abstract}

Palavras-chave: Transformações Geométricas no Plano, Recursos Computacionais, Ensino e Aprendizagem de Matemática.

\section{EXPLORING FRIEZES AND FLOORS' GEOMETRY THROUGH GEOGEBRA SOFTWARE}

\begin{abstract}
The purpose of this work is to present some partial results from a qualitative research carried out with $6^{\text {th }}$ grade from Elementary School, by using the Didactic Engineering. Geometric transformations on the plane such as, reflections, translations and rotations were approached aiming to observe the contributions of employing a computer program, as the GeoGebra, to the Math teaching. Besides this purpose, an html page was elaborated with activities about these topics. We can infer, from the analysis of the results, that the use of these computer resources promoted an interactive environment in classroom, favoring an intuitional approach and of geometry experimentation, which aroused the students' investigative spirit and made them active participants in the learning process.
\end{abstract}

Key-words: Geometric Transformations on the Plane, Computer Resources, Math Teaching and Learning.

\section{Introdução:}

A procura por aulas diferentes em que é possível desafiar os alunos a buscarem caminhos para a construção do conhecimento motiva o professor a procurar ferramentas

\footnotetext{
${ }^{1}$ Este relato faz parte da dissertação elaborada no curso de Mestrado Profissionalizante me Ensino de Física e de Matemática da Unifra - RS.
} 
que o auxilie no ensino e na aprendizagem dos alunos. Para tanto, ele necessita conhecer e aplicar novas metodologias para o ensino da Matemática em diferentes áreas, a fim de realizar um trabalho interdisciplinar.

Nesse trabalho, conjugou-se Arte e Matemática, explorando os ladrilhos e frisos presentes nas Igrejas Matrizes da Quarta Colônia de Imigração Italiana, do Rio Grande do Sul, bem como o uso de recursos computacionais para ensinar Geometria de forma dinâmica e, assim, estimular o aluno a apreciar a Arte por meio da Matemática.

As simetrias, translações e rotações, presentes nos frisos e ladrilhos, foram fontes motivadoras para o desenvolvimento de atividades geométricas em sala de aula. Foi elaborada uma sequência didática composta de atividades referentes às transformações geométricas no plano, as quais foram exploradas por meio de um software de Geometria Dinâmica como o GeoGebra. Essas atividades foram apresentadas aos alunos em uma página html, construída com o propósito de trabalhar as atividades da sequência didática, em sala de aula, com uma turma de sexta série do Ensino Fundamental.

\section{Explorando os Frisos e Ladrilhos no GeoGebra}

A Arte oferece inúmeras opções para mostrar a Geometria de forma contextualizada e cabe ao professor buscar a forma mais eficaz de explorá-la.

A Quarta Colônia de Imigração Italiana, composta por sete municípios, situa-se na região central do Rio Grande do Sul. Tais municípios são unidos pelas origens culturais e religiosas, cujo uso de elementos dessa cultura regional, como os frisos e ladrilhos presentes nas Igrejas Matrizes, foram aproveitados em sala de aula como forma de transpor para a Matemática escolar, os conhecimentos oriundos da cultura do povo. Os frisos e ladrilhos compostos de figuras geométricas mostram como a Matemática e a Arte se integram, apresentando uma grande potencialidade pedagógica, cujas formas geométricas foram exploradas em atividades de sala de aula.

As aulas que envolvem algum aspecto ligado a Arte assumem concepções de caráter expressivo, mostram-se como espaços de invenção, autonomia e descobertas, buscam a espontaneidade, baseando-se principalmente na autoexpressão dos alunos.

Ao conectar Geometria e Arte, no trabalho pedagógico com alunos do Ensino Fundamental, lançou-se mão de ferramentas computacionais que permitiram a exploração e a visualização, favorecendo o processo de ensino-aprendizagem dos conceitos geométricos. As reflexões, translações e rotações presentes nos frisos e ladrilhos, foram fontes ricas e motivadoras para o desenvolvimento de atividades geométricas e contribuíram tanto para o desenvolvimento do raciocínio geométrico, como para a criação da sensibilidade estética dos alunos.

Outra fonte motivadora para o ensino de Geometria foi o uso de um software de Geometria Dinâmica como o GeoGebra, que contribuiu para a melhoria do aprendizado da Matemática.

De acordo com Gravina e Santarosa (1998, p.25):

Não são de interesse as ferramentas que guardam características de métodos de ensino que privilegiam simplesmente a transmissão do conhecimento e em que a "medida" de aquisição deste conhecimento é dada pela habilidade do aluno em memorizá-lo e reproduzi-lo, sem que evidencie um verdadeiro conhecimento. Mas sim aquelas que trazem em seus projetos recursos em consonância com concepção de aprendizagem dentro de uma abordagem construtivista, a qual tem como princípio que o conhecimento é construído a partir de percepções e ações do sujeito [...]. 
Assim, o uso de recursos computacionais no ensino de Matemática tornou-se uma ferramenta essencial que deve ser utilizada em sala de aula. Esse fato não pode ser ignorado pelo professor, o qual deve compreender o caminho percorrido pelo aluno para construção do conhecimento e, dessa forma, criar condições favoráveis para que esse caminho se realize.

Quando possível, o professor deve aumentar a interação entre a sala de aula e o laboratório de informática, estabelecendo uma união entre ambos. A introdução dos ambientes computacionais no ensino faz com que o professor conheça novas metodologias de ensino e de aprendizagem. Gravina (1996) manifesta-se favoravelmente à utilização de ferramentas computacionais no ensino de Geometria.

\footnotetext{
Vemos emergir uma nova forma de ensinar e aprender Geometria; a partir de exploração experimental viável somente em ambientes informatizados, os alunos conjeturam e, com o feedback constante oferecido pela máquina, refinam ou corrigem suas conjeturas, chegando a resultados que resistem ao "desenho em movimento", passando então para a fase abstrata de argumentação e demonstração matemática. (p. 2)
}

O objetivo da introdução do computador na educação não deve consistir apenas em um modismo ou simplesmente estar atualizado com as inovações tecnológicas, mas é importante que seja utilizado efetivamente no processo de desenvolvimento da capacidade de criar e pensar, além de ser usado como uma ferramenta que facilita a reflexão, o pensamento crítico e, de acordo com Valente (1993), que promova: “[...] a aprendizagem ao invés do ensino, que coloca o controle do processo de aprendizagem nas mãos do aprendiz, e que auxilia o professor a entender que a educação não é somente a transferência de conhecimento, mas um processo de construção de conhecimento pelo aluno [...]" ( p. 40).

Somente atividades que desafiem e motivem os alunos, que os auxiliem a refletir podem contribuir no processo de ensinar e de aprender com eficácia. O uso dos computadores deve ser positivo quando não é usado como um acessório, mas sim, como um instrumento a serviço do processo de ensino e aprendizagem.

O ensino da Geometria foi uma das áreas da Matemática que se beneficiou com o uso dos computadores nas escolas, pela utilização dos softwares de Geometria Dinâmica.

A Geometria Dinâmica é uma mistura entre desenho geométrico e laboratório virtual, pelo fato de valorizar a construção com régua e compasso, com uma dimensão dinâmica, que potencializa a investigação e amplia as possibilidades de exploração dos conceitos geométricos. Para Gravina (1996), a Geometria Dinâmica proporciona uma nova abordagem ao aprendizado geométrico, em que conjecturas são feitas a partir da experimentação e criação de objetos geométricos. A autora afirma que os ambientes de Geometria Dinâmica:

[...] são ferramentas informáticas que oferecem régua e compasso virtuais, permitindo a construção de objetos geométricos a partir das propriedades que os definem. São micromundos que caracterizam um domínio teórico, no caso da geometria euclidiana, pela construção de seus objetos e de representações que podem ser manipuladas diretamente na tela do computador. (2001, p. 82)

Os softwares de Geometria Dinâmica permitem ao aluno trabalhar de forma experimental, podendo, assim, interagir com conceitos matemáticos e investigar propriedades e relações. 
Nessa pesquisa, optou-se pela escolha do software GeoGebra. A escolha desse software ocorreu pelo fato de possuir recursos essenciais para construção e exploração de transformações geométricas no plano, além de ser gratuito. As construções feitas neste software são muito parecidas com as realizadas com lápis e papel. Ele possui uma boa interface que possibilita a exploração e a manipulação rápida das figuras, além de possibilitar a medição de ângulos distâncias, transladar, girar e refletir, ações essas necessárias para explorar as transformações geométricas no plano.

O GeoGebra permite criar paginas web interativas, chamadas Folhas de Trabalho Dinâmicas, o que permite que, em uma página $h t m l$, se trabalhe diretamente com o software.

Ao utilizar esse programa, os alunos podem explorar as propriedades de uma figura geométrica, que os auxilia a tornar mais claro os conceitos. Isso quer dizer que eles podem analisar as características específicas de uma figura e estabelecer relações e descobrir propriedades.

A utilização desse programa computacional, nas aulas de Matemática, foi eficaz pois, possibilitou aproveitar as estratégias dos alunos de movimentar as figuras e verificar quais as propriedades que se conservavam ao refletir, transladar ou rotacionar uma figura.

\section{A experiência realizada}

A metodologia utilizada para a realização dessa pesquisa baseou-se na Engenharia Didática que, de acordo com Pais (2002), "é caracterizada como uma forma particular de organização de procedimentos metodológicos da pesquisa em didática da Matemática.” (p. 99).

De acordo com Artigue (1996), a Engenharia Didática prevê etapas de análises prévias, concepção e análise a priori de experiências didático-pedagógicas, experimentação, aplicação da sequência didática, análise a posteriori e validação.

A sequência de ensino elaborada foi disponibilizada em uma pagina $\mathrm{html}$, onde os alunos desenvolveram seus trabalhos e a avaliação ocorreu confrontando os dados obtidos durante a realização da atividade com aqueles descritos na análise $a$ priori.

A Figura 1 mostra a tela inicial onde foram apresentados os objetivos da sessão.

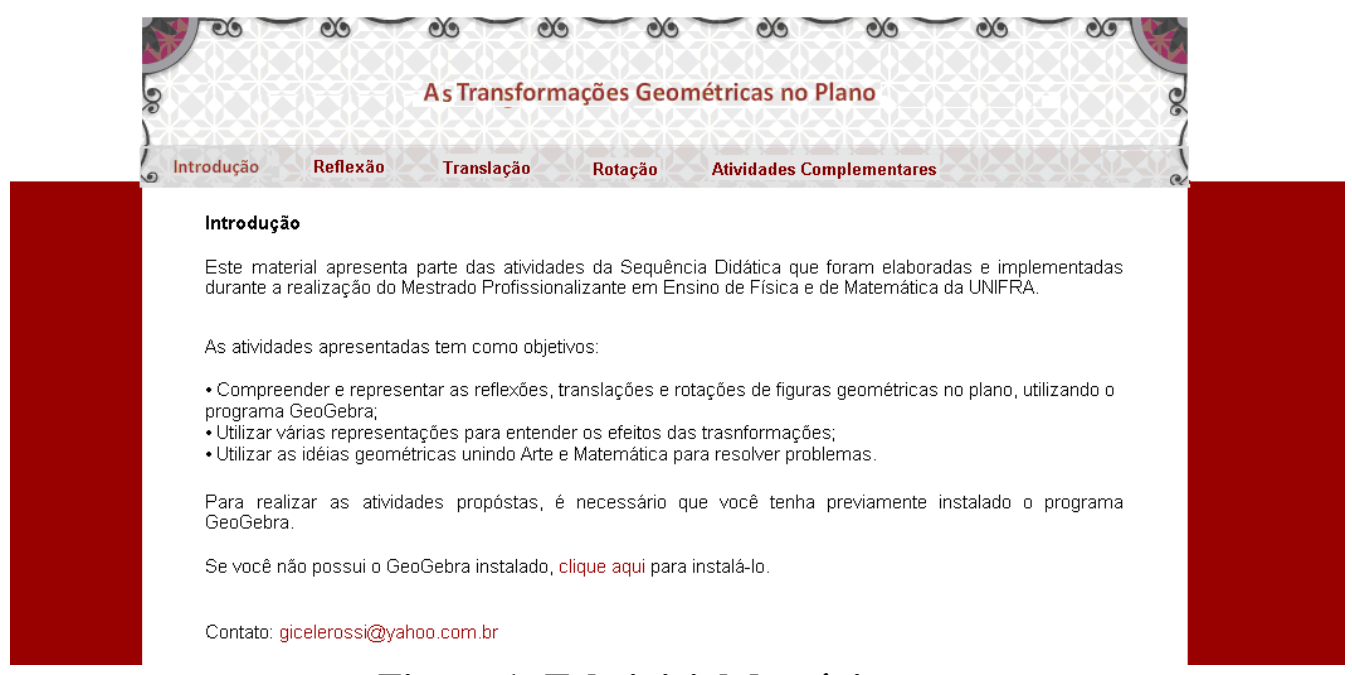

Figura 1: Tela inicial da página. 
São apresentadas a seguir algumas das atividades desenvolvidas com os alunos em sala de aula.

Atividade 1- Desenhe nas imagens os eixos que você identifica. Represente pontos e figuras simétricas na composição dos pisos.

O propósito dessa atividade era que os alunos identificassem os eixos de simetria e desenhassem esses eixos, de acordo com sua própria exploração e percepção. Pretendeu-se, no desenvolvimento dessa atividade, que o aluno assumisse uma atitude exploratória e investigativa e, que a partir disso, daí pudesse entender o conceito de eixo de simetria, pontos simétricos e figuras simétricas.

Observou-se, na análise dessa atividade e dos comentários feitos durante a realização da atividade, que os alunos tiveram uma boa percepção do conceito de eixo de simetria, pontos simétricos e figuras simétricas. Eles comentaram:

"O eixo de simetria divide a figura ao meio".

A figura abaixo mostra a análise de uma das duplas de alunos. A construção de eixos de simetria feita por uma das duplas de alunos mostrada na figura 2 , comprova essa conclusão.

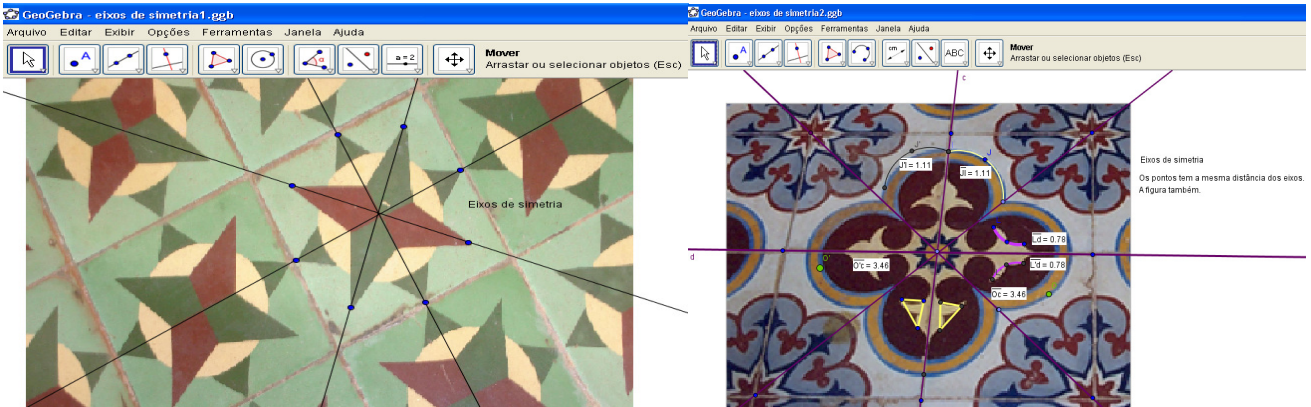

Figura 2: Desenho dos eixos de simetria realizado por uma dupla de alunos.

Com o GeoGebra os alunos puderam traçar os eixos na própria imagem e verificar as propriedades que envolvem o conceito "eixo de simetria".

Em relação aos pontos simétricos e figuras simétricas foram constatados os comentários abaixo:

"Se temos um ponto e fizemos o simétrico dele, podemos ver que o ponto simétrico só se move quando movemos o ponto original."

"As distâncias entre o ponto e o simétrico dele é a mesma até a reta."

"Se temos uma figura, a figura simétrica só se move quando movemos a que foi feita primeiro."

"A distância do polígono original até a reta é a mesma do polígono simétrico até a reta."

Percebeu-se pelas respostas dos alunos, mesmo não sendo formais, que eles souberam elaborar suas conclusões, bem como perceberam que a distância de um ponto da figura original até o eixo de simetria é a mesma distância de seu ponto simétrico até o eixo de simetria, na figura refletida.

A figura abaixo mostra uma das representações dos alunos em relação aos pontos simétricos e a polígonos simétricos. 


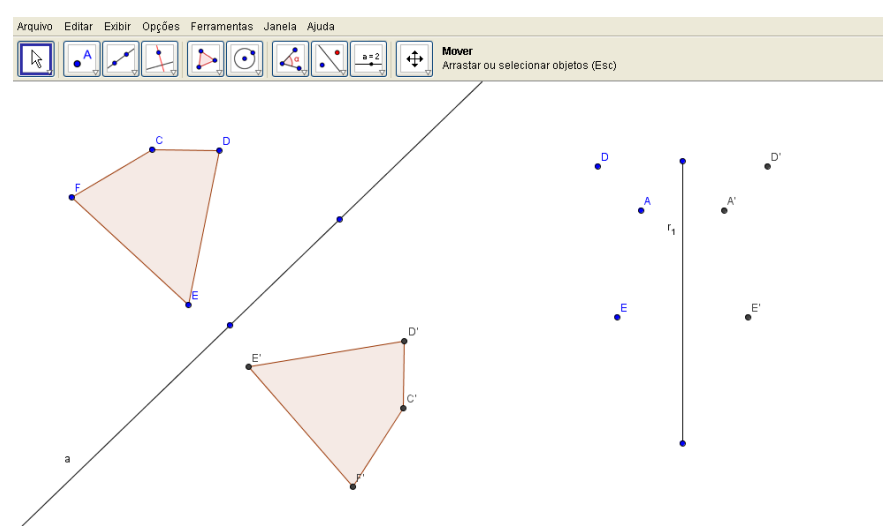

Figura 3: Pontos e figuras simétricas exploradas pelos alunos.

Atividade 2- Analise o desenho do friso e do piso e trace um eixo de simetria de modo a obter uma figura refletida em relação ao eixo traçado.

Esta atividade foi elaborada com o propósito dos alunos verificarem na composição da imagem do friso e do piso a presença da reflexão de figuras em relação aos eixos de simetria.

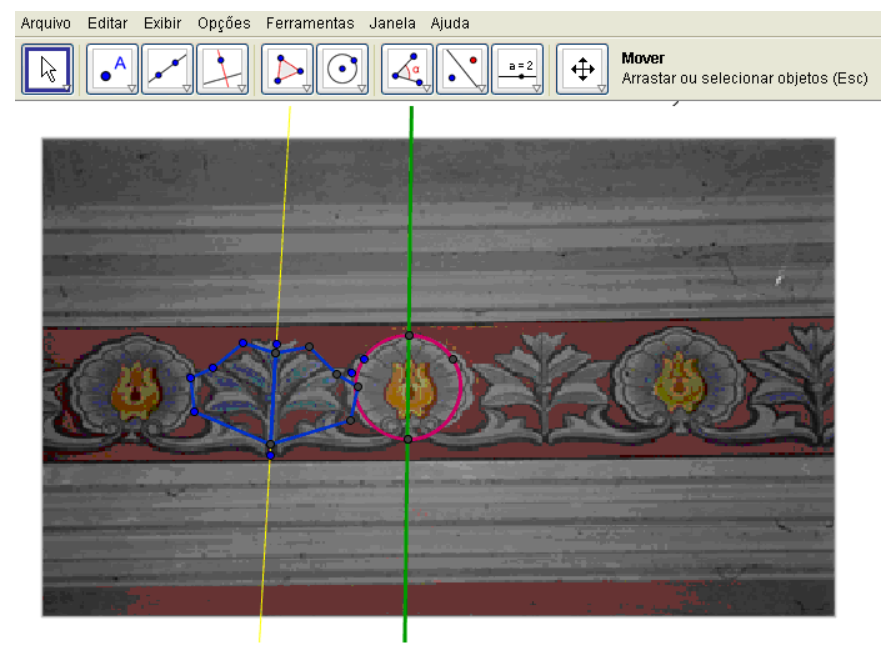

Figura 4: Eixos de simetria e reflexão identificada por uma dupla.

Tanto no friso como no piso percebeu-se que os alunos identificaram os eixos de simetria vertical e horizontal que estes desenhos apresentam bem como a reflexão em relação a cada eixo.

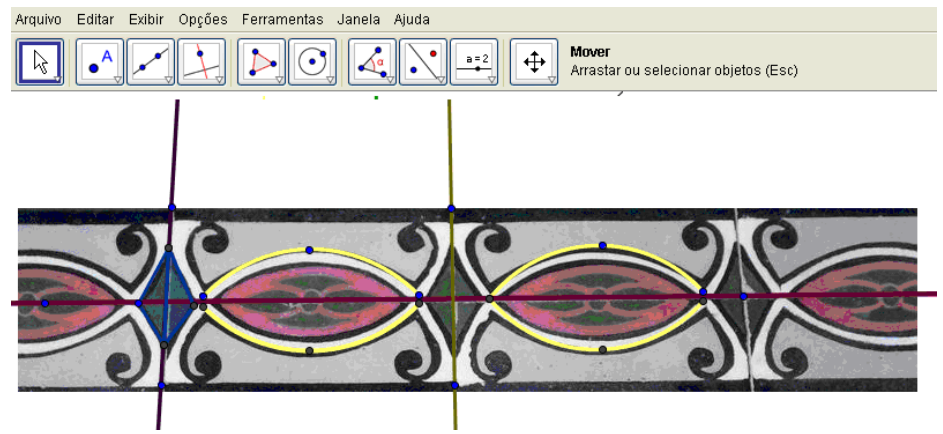

Figura 5: Eixos de simetria e reflexão representados por uma dupla. 
Atividade 3- Analise os frisos a seguir e identifique se houve uma translação. Justifique sua resposta.

Essa atividade teve como propósito a identificação, na composição dos frisos, a transformação geométrica translação.

Primeiramente os alunos identificaram o motivo que se repetia em cada friso e, antes de realizar a translação, perceberam que na composição dos frisos a reflexão estava presente, assim reconstruíram o friso de forma semelhante, fazendo reflexões e após as translações. envolvidos.

Percebe-se nas construções dos alunos o entendimento dos conceitos

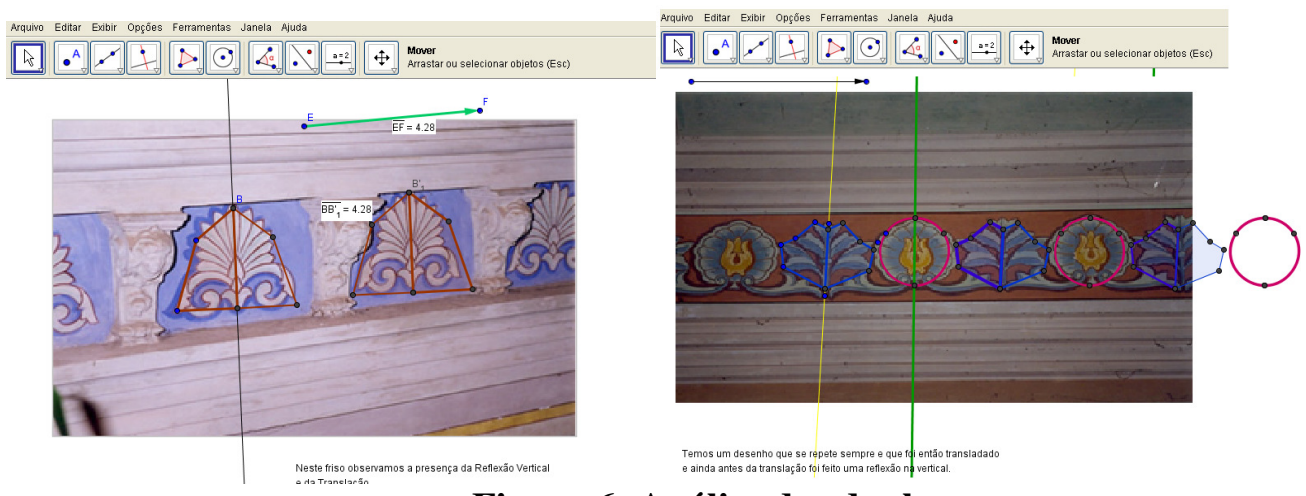

Figura 6: Análise das duplas.

Durante a realização dessa atividade a professora levantou questionamentos.

"Se você mudar o tamanho e a posição do vetor. $O$ que acontece com o friso que você reproduziu?"

"A translação de uma figura é sempre a mesma, isto é, conserva o tamanho e a forma da figura?"

Os alunos fizeram alguns comentários, dos quais pode-se destacar:

"Percebemos que a figura vai de acordo com a direção do vetor e que o comprimento do vetor é o mesmo que a distância das figuras."

"As figuras ficam sempre iguais."

Atividade 4- Analise a composição do friso e identifique se houve uma rotação.

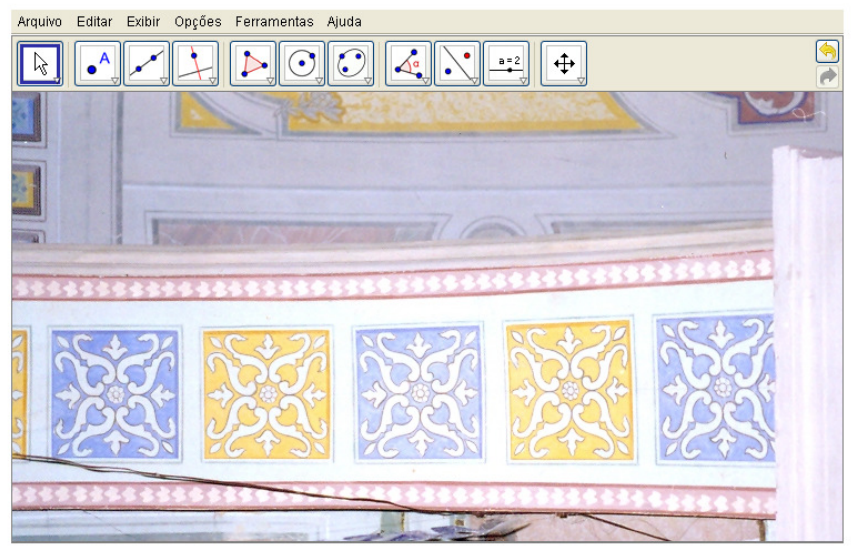

Figura 7: Friso da Igreja Santo Antonio de Silveira Martins. 


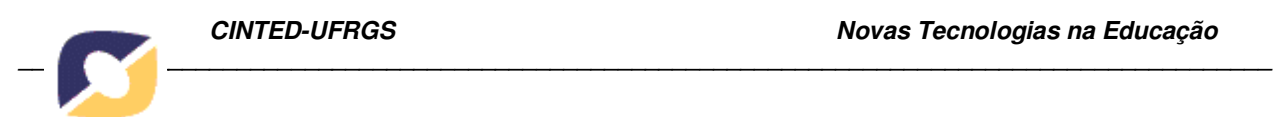

Uma das produções dos alunos pode-se perceber na figura 7.

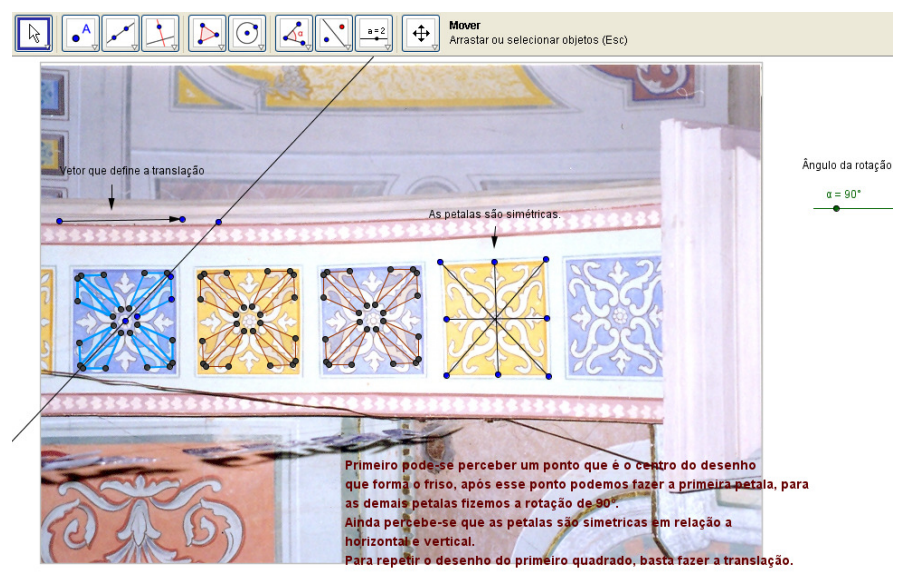

Figura 8: Representação dos alunos.

Nessa construção, os alunos desenharam os eixos de simetria e explicaram que fizeram uma rotação de um ângulo de noventa graus $\left(90^{\circ}\right)$. Em uma das explicações feitas por um dos alunos pôde-se perceber a compreensão do movimento rotação.

"Dá para ver que na figura foi feita apenas com uma pétala, e que depois essa pétala foi girando em torno de um ponto do centro, não dá para ter certeza no ângulo, no desenho fizemos uma boa aproximação."

Atividade 5- Use sua criatividade e desenhe um friso e um piso.

Nessa atividade, os alunos foram instigados a produzirem frisos e pisos. Ela teve também um caráter lúdico, pois os alunos se envolveram na criação dos desenhos e no uso de diferentes cores. Nesse trabalho, ficou evidenciada a relação entre Arte e Matemática, e os alunos mostraram um bom domínio dos recursos do software para fazer a representação semelhante ao piso.
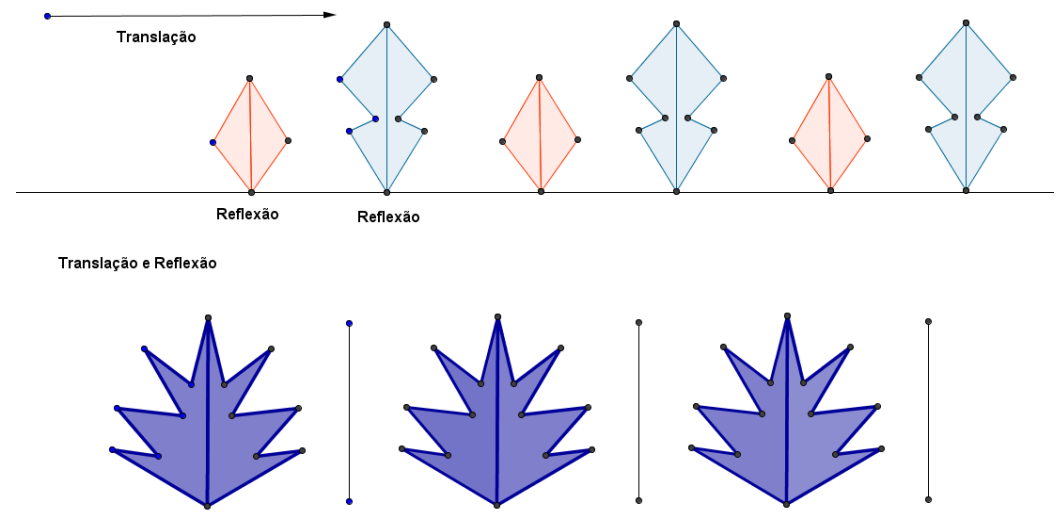

Figura 9: Frisos feitos por uma das duplas.

Os desenhos abaixo mostram que os alunos tentaram reproduzir alguns pisos presentes nas Igrejas. 

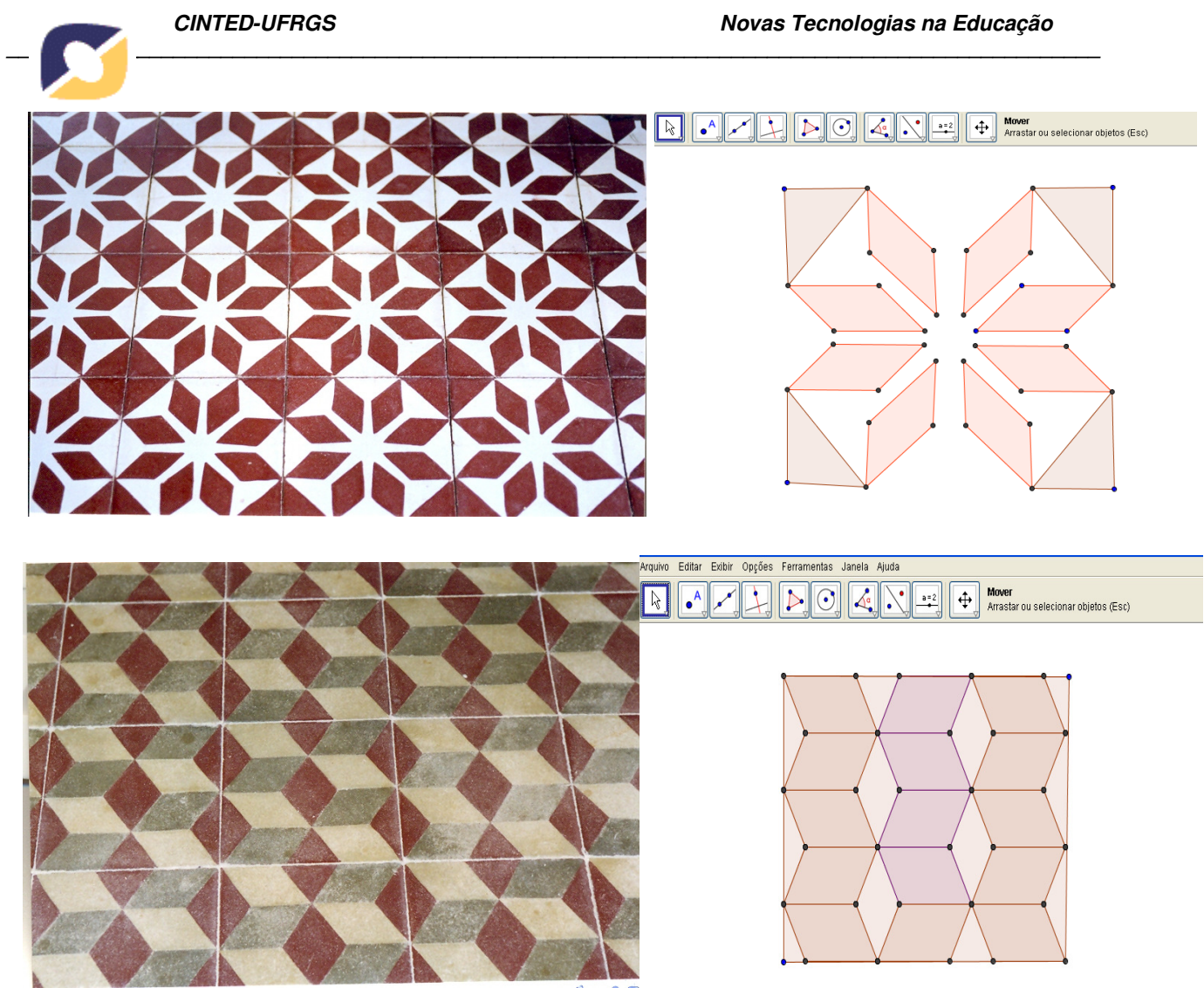

Figura 11: Pisos das Igrejas e construções dos alunos.

A ação investigativa desencadeada a partir da análise dos frisos presentes nas Igrejas da Quarta Colônia propiciou aulas dinâmicas, com muitas explorações, em que os alunos se envolveram na descoberta e nas representações, utilizando as formas presentes nos frisos das Igrejas como fonte motivadora para criar seus próprios desenhos. A partir das diferentes representações explorou-se o conceito de reflexão e translação.

As atividades descritas são apenas algumas das que foram desenvolvidas durantes a aplicação da Sequência Didática aos alunos.

As conclusões sobre a eficácia da utilização de recursos computacionais no desenvolvimento das atividades, foram elaboradas a partir da análise dos caminhos percorridos pelos alunos na busca de solução, os quais foram registrados no diário de campo da professora.

\section{Considerações Finais}

Nesse trabalho buscou-se mostrar o resultado da aplicação de um software de Geometria Dinâmica, juntamente com a análise de frisos e pisos compostos por formas geométricas encontrados nas Igrejas da Quarta Colônia de Imigração Italiana do Rio Grande do Sul, na exploração das transformações geométricas tais como a reflexão, translação e rotação.

Os resultados apresentados nas soluções elaboradas pelos alunos mostraram que as atividades da sequência didática desenvolvida, conjugando Arte e Matemática de forma interdisciplinar, contribuíram para a aprendizagem dos alunos e, a utilização do GeoGebra, auxiliou-os na visualização e na investigação das propriedades geométricas.

Além de contribuir para a efetiva construção do conhecimento matemático, esse trabalho interdisciplinar, mediado por um recurso computacional, possibilitou o 
desenvolvimento de habilidades como a criatividade, o raciocínio lógico, despertou o gosto pelo estudo e auxiliou os alunos a compreenderem os valores culturais e estéticos, importantes para apreciação das obras artísticas.

Os ladrilhos e frisos, vibrantes pelo colorido e pelas formas geométricas e projetados com uma simetria e rebatimentos quase exatos, foram fontes motivadoras de estudo que deram significado aos conceitos geométricos envolvidos.

\section{Referências Bibliográficas:}

ARTIGUE, Michele. Engenharia Didática. In: BRUN, Jean. Didáticas das Matemáticas. Lisboa: Instituto Piaget. Horizontes Pedagógicos, 1996.

FAINGUELERNT, Estela Kaufman; NUNES, Kátia Regina Ashton. Fazendo Arte com a Matemática. Porto Alegre: Artmed, 2006.

GRAVINA, Maria Alice: Geometria Dinâmica: Uma nova abordagem para o aprendizado da Geometria. Publicado nos Anais do VII Simpósio Brasileiro de Informática na Educação, Belo horizonte, Brasil, nov 1996.

GRAVINA, Maria Alice; SANTAROSA, Lucila Maria. A aprendizagem Matemática em Ambientes Informatizados. Anais do IV Congreso Iberoamericano de Informática Educativa, v. 1, Brasília, p. 25-35, 1998.

PAIS, Luiz Carlos. Didática da Matemática: uma análise da influência francesa. Belo Horizonte: Autêntica, 2002.

VALENTE, José Armando. Computador na sociedade do conhecimento. Campinas: Nied, 2002. 